\title{
OS ADMINISTRADORES NÃO EXECUTIVOS DAS EMPRESAS COTADAS NA EURONEXT LISBON - UMA ABORDAGEM EMPÍRICA
}

\section{THE NON-EXECUTIVE DIRECTORS OF LISTED COMPANIES IN EURONEXT LISBON - AN EMPIRICAL APPROACH}

\author{
Pedro Verga Matos \\ Professor Associado da Lisbon School of Economics \& Management (ISEG) - Universidade de Lisboa. \\ Lisboa, Portugal \\ E-mail: pvmatos@iseg.ulisboa.pt
}

Ana Maria Evans

Professora da Nova Information Management School (Nova IMS) - Universidade Nova de Lisboa

Lisboa, Portugal

E-mail: a.evans@novaims.unl.pt

Tânia Bento Tomás

Lisbon School of Economics \& Management (ISEG) - Universidade de Lisboa.

Lisboa, Portugal

E-mail: taniatomas@hotmail.com

\section{RESUMO}

Sendo os escândalos financeiros e as falências empresariais uma realidade cada vez mais frequente na nossa sociedade, o papel desempenhado pelos administradores não executivos nos Conselhos de Administração das empresas torna-se ainda mais importante para a resolução desta problemática, uma vez que estes procuram o alinhamento de interesses entre os accionistas e os gestores. Pretende-se com este estudo identificar quais os factores que determinam o grau de representação dos administradores não executivos no Conselho de Administração das empresas cotadas na Euronext Lisbon e analisar o impacto que a sua presença tem na remuneração dos administradores e no desempenho da empresa. Os resultados sugerem que a dualidade do CEO e a adesão ao PSI20 reduzem a percentagem de não executivos presente nos Conselhos de Administração enquanto a dimensão do Conselho tem um efeito positivo. Consta-se, ainda, que estes administradores não estão a cumprir o seu papel de controlo no que diz respeito à política remuneratória e ao desempenho da empresa.

Palavras-chave: Administradores não executivos. Teoria da Agência. Euronext Lisbon. Governo das Empresas. Crise financeira.

\section{ABSTRACT}

Financial scandals and corporate bankruptcies have been very common in our society. The role of nonexecutive directors on the Boards of Directors of companies becomes even more important to the resolution of this problem, since they seek alignment of interests between shareholders and managers. The aim of this study was to identify the factors that determine the degree of representation of nonexecutive directors on the Board of Directors of the companies listed on Euronext Lisbon and analyze the impact they have on directors' remuneration and company performance. Our results suggest that the duality of CEO and adherence to PSI20 reduce the percentage of non-executive directors on the Boards of Directors present while the size of the Board has a positive effect. We note also that these administrators are not fulfilling their role of control in respect of the remuneration policy and company performance.

Keywords: Non executive director. Agency theory. Euronext Lisbon. Corporate governance. Financial crisis.

Data de submissão: 12 de janeiro de 2018.

Data de aprovação: 25 de abril de 2018.

Pedro Verga Matos agradece o financiamento por fundos nacionais através da FCT - Fundação para a Ciência e a Tecnologia no âmbito do projecto com a referência UID/SOC/04521/2013.

Ana Maria Evans agradece o apoio financeiro à investigação pelo Projecto FCT IF/00827/2013/CP1169/CT0001. 


\section{INTRODUÇÃO}

Nos últimos anos tem-se assistido a falências de grande dimensão e visibilidade e a notícias sobre elevadas remunerações pagas aos seus administradores, situações que permitem questionar a eficácia dos actuais modelos de governo das sociedades. A crise financeira que foi desencadeada pelo mercado subprime nos EUA evidenciou falhas nos modelos e mecanismos de governo das empresas em diversos países (ERKENS et al, 2012; GUPTA et al., 2013; KIRKPATRICK, 2009; SIKKA, 2009). Em particular, foi questionado o funcionamento dos Conselhos de Administração (boards) e a relevância da sua composição e características dos seus membros no bom desempenho das empresas (ADAMS, 2012).

A literatura existente sugere que os administradores não executivos devem proteger os interesses dos accionistas nas decisões mais importantes da empresa (BEBCHUCK e WEISBACH, 2010). Eles são vistos como o principal elemento responsável por controlar e combater qualquer comportamento oportunista por parte dos seus colegas executivos (HELLAND e SYKUTA, 2005; LONG et al., 2005). Porém, a eficácia da sua função de controlo pode ser contestada, por exemplo, se os administradores não executivos não forem efectivamente independentes (FERNANDES, 2008).

O presente trabalho empírico tem como objectivo estudar os administradores não executivos das empresas cotadas na Euronext Lisbon num horizonte temporal de quatro anos (2006 a 2009), analisando o seu papel do governo dessas empresas. Para o efeito, foram realizadas várias regressões (com base em dados recolhidos sobre todas as 40 empresas cotadas naquela bolsa de valores) que pretendem determinar quais os factores que mais impacto têm no grau de representação dos administradores não executivos nos Conselhos de Administração, nomeadamente, a dimensão da empresa, estrutura accionista e dualidade do CEO. Também se procurou estudar a situação complementar, ou seja, a influência dos administradores não executivos (medidos pela sua representatividade no Conselho de Administração) sobre a remuneração dos administradores e o desempenho da empresa.

Espera-se com este trabalho contribuir para o debate sobre a importância dos administradores não executivos no bom governo das empresas, sobre a qual os resultados empíricos são mistos, estudando uma pequena bolsa de valores europeia, num período significativo e importante.

\section{REVISÃO DA LITERATURA}

\section{Administradores Não Executivos - Enquadramento Global}

Na empresa moderna, onde há uma separação entre a propriedade e a gestão, a teoria da agência foca-se sobre a relação entre o principal (accionista) e o agente (gestor), sendo dever deste salvaguardar o valor para os accionistas. No entanto, frequentemente assistimos a situações em que os gestores de uma empresa têm comportamentos oportunistas que entram em conflito com os interesses dos accionistas, dando origem ao denominado "problema de agência", identificado pela primeira vez por JENSEN e MECKLING (1976). ${ }^{i}$

Neste contexto, têm surgido vários estudos sobre os mecanismos de controlo que mitigam estes conflitos e melhoram o alinhamento de interesses dentro de uma empresa, sendo de destacar o Conselho de Administração (BATHALA e RAO, 1995; BOYD; 1994; CONYON e PECK, 1998; REINA, 2012; RHOADES et 
al., 2001; SILVA et al., 2011; WALSH e SEWARD, 1990; ZAJAC e WESTPHAL,1994), e em especial a sua composição. BATHALA e RAO (1995) notam que o Conselho reduz os conflitos de agência ao manter separadas as responsabilidades de gestão e de controlo no processo de tomada de decisão, posição também defendida por DESENDER et al (2013) e FINEGOLD et al (2007).

A estrutura de governo correntemente adoptada pelas empresas Portuguesas cotadas é a estrutura monista. Neste sistema, o Conselho de Administração das empresas é constituído pelo CEO e por outros administradores, que podem ser executivos ou não executivosii. Enquanto os primeiros estão incumbidos de gerir e fornecer informações importantes sobre as actividades da empresa, o principal papel delegado aos membros não executivos é controlar a gestão da empresa (FERNANDES, 2008). É, ainda, comum referir-se que para desempenharem adequadamente as suas funções, os administradores não executivos devem ser independentesiii.

Embora exista alguma variação na terminologia, têm sido atribuídos três papéis principais ao administrador não executivo: controlo, serviço e dependência de recursos (JOHNSON et al., 1996). No seu papel de controlo, espera-se que os não executivos protejam os interesses dos accionistas, utilizando o seu conhecimento e objectividade na avaliação e controlo das decisões dos gestores (LI, 1994), de modo a combater qualquer tendência de comportamento oportunista por parte destes. Desta forma, eles devem "colmatar a lacuna existente entre os accionistas desinformados e os administradores executivos plenamente informados" (FERNANDES, 2008, p. 33), "na tentativa de resolver, ou pelo menos atenuar, os conflitos de agência entre gestores e accionistas" (BATHALA e RAO, 1995, p. 59).

Long et al. (2005, p. 668) afirma que o papel do administrador não executivo é frequentemente descrito como "o autor das decisões baseadas no consenso", e HIGGS (2003, p. 11) assegura que este funciona como "o guardião do processo de governo" ("the custodian of the governance process"). Para além disso, BATHALA e RAO (1995, p. 60) defendem que, ao contrário do que pode acontecer com os executivos, os administradores não executivos "não sofrem de pensamento de grupo ou de modos de comportamento subordinado" porque as suas reputações de "árbitros profissionais" estão em causa.

A eficácia dos administradores não executivos também tem sido reconhecida pelos reguladores e mercados de valores mobiliários. Por exemplo, em 2003, a New York Stock Exchange (NYSE) e o NASDAQ Stock Market (NASDAQ) adoptaram novas práticas de bom governo onde, nomeadamente, consideram que as sociedades cotadas devem ter uma maioria de administradores não executivos.

No entanto, existem também razões para sugerir que os administradores não executivos não controlam a gestão conforme pretendido pelos accionistas (BATHALA e RAO, 1995; BAYSINGER e HOSKISSON, 1990; CONYON e PECK, 1998; LONG et al., 2005; ZAJAC e WESTPHAL, 1994). Uma dessas razões reside no facto de os não executivos terem poucas participações no capital da empresa (FINKELSTEIN e HAMBRICK, 1996).

A segunda razão contesta a hipótese de que os não executivos são independentes da influência dos executivos, uma vez que poderão ter sido nomeados pelo CEO da empresa (CONYON e PECK, 1998; SHIVDASANI e YERMACK, 1999; WESTPHAL e ZAJAC, 1995) ou se anteriormente foram membros da equipa de gestão da empresa (BAYSINGER e HOSKISSON, 1990). Em terceiro lugar, a ineficácia dos administradores não executivos pode ser explicada pela falta de um mercado para a reputação ("market for reputation"). Assim, se não existir um mercado de trabalho para os administradores não executivos ou se este 
for ineficiente, a construção de uma reputação como defensores eficazes dos interesses dos accionistas não será importante para eles (FERNANDES, 2008)iv, pelo que poderão não exercer de forma independente a sua função.

Importa, ainda, salientar a assimetria de informação existente entre os dois tipos de administradores (executivos e não executivos). Esta situação leva a que os executivos tenham superioridade de informação relativamente aos não executivos, obrigando estes a depender fortemente da interpretação dos primeiros. Por último, se os não executivos estiverem presentes em diferentes Conselhos "podem não conseguir compreender suficientemente bem cada negócio para serem realmente eficazes" (BATHALA; RAO, 1995, p. 60 ), havendo por isso, nestes casos, alguma tendência para votar no sentido sugerido pelos executivos.

\section{Estudos Empíricos Sobre os Determinantes da Representação dos Administradores Não Executivos}

\section{Dimensão da empresa}

De acordo com a literatura, uma importante variável na análise dos determinantes da representação dos administradores não executivos nas sociedades cotadas é a dimensão da empresa, cuja mensuração é realizada com base em diferentes indicadores - O'SULLIVAN (2000), por exemplo, utiliza a capitalização de mercado, enquanto FERNANDES (2008) usa o total das vendas.

Os resultados destes estudos têm sido mistos. Alguns investigadores, tais como, FERNANDES (2008), LI (1994) e O'SULLIVAN (2000) verificaram que a dimensão da empresa tem um efeito positivo sobre o grau de representação dos administradores não executivos. De acordo com O'SULLIVAN (2000), este resultado é consistente com a noção de que, com o aumento da dimensão da empresa, o controlo exercido pelos accionistas individuais através da posse de participações significativas é mais difícil e menos eficiente, e por isso, as empresas recorrem a outros mecanismos de governance, nomeadamente, aos administradores não executivos. Segundo FERNANDES (2008, p. 33), "embora a dimensão do Conselho de Administração aumente claramente com a dimensão da empresa, a tendência é ainda mais clara para os membros não executivos do Conselho". Contudo, existem estudos que referem que a dimensão da empresa não tem qualquer influência sobre a composição do Conselho como é o caso de BATHALA e RAO (1995) e KREN e KERR (1997).

\section{Estrutura accionista}

A estrutura de propriedade é considerada por vários autores como um importante factor de controlo e vigilância do Conselho (HAMBRICK e FINKELSTEIN, 1995; TOSI e GOMEZ-MEJIA, 1994; ZAJAC e WESTPHAL, 1994), influenciando a sua composição.

Existem, conceptualmente, dois grandes tipos de estruturas de propriedade das empresas: dispersa e concentradav (LI, 1994). Enquanto nos países marcados pela concentração da propriedade (sobretudo os países da Europa continental), os membros dos Conselhos de Administração são, frequentemente, os accionistas maioritários da empresa ou pessoas da sua confiança (existindo o risco de expropriação dos accionistas minoritários), nos Conselhos das empresas dos países anglo-saxónicos, os accionistas não têm capacidade para se fazerem representar directamente, pelo que os administradores, normalmente, estão 
divididos em administradores executivos e administradores não executivos, os quais possuem um certo conhecimento e nenhuma participação accionista (LI, 1994; SILVA et al., 2006).

A literatura sugere que a concentração de propriedade e o uso de administradores não executivos são mecanismos de governo alternativos utilizados pelas empresas, uma vez que estes poderão compensar o controlo possivelmente enfraquecido de accionistas dispersos. O trabalho de LI (1994) está de acordo com esta hipótese, pois revela que o controlo do Conselho de Administração, medido pela percentagem de administradores não executivos nos Conselhos está negativamente relacionado com a concentração de propriedade. No entanto, os resultados de O'SULLIVAN (2000) mostram que a propriedade dos grandes accionistas tem um efeito positivo e significativo sobre a percentagem de não executivos utilizados pelas empresas.

Embora os administradores não executivos forneçam ao Conselho uma importante função de controlo, na tentativa de reduzir os conflitos de agência, BATHALA e RAO (1995) e BECHT et al. (2003) indicam que outros mecanismos, tais como, a participação accionista dos investidores institucionais e da gestão também servem como instrumentos importantes no alinhamento de interesses entre gestores e accionistas. Uma série de estudos tem sugerido que os accionistas institucionais podem obter um controlo mais activo do comportamento dos gestores (por exemplo, BATHALA e RAO (1995) e O'SULLIVAN (2000)), frequentemente através da obtenção de lugares no Conselho de Administração (ver BOYD (1994))vi. Relativamente à participação accionista da gestão, JENSEN E MECKLING (1976) e O'SULLIVAN (2000) notam que, quando a percentagem de capital detida pelo gestor aumenta, é menos provável que este aceite a utilização excessiva de bónus ou se afaste demasiado da maximização do lucro, tornando os interesses do principal e do agente estritamente mais alinhados.

\section{Dualidade do CEO}

Nos estados membros da União Europeia coexistem duas modalidades de estruturas de administração e fiscalização: o sistema monista e o sistema dualista (SILVA et al., 2006) vii. O primeiro sistema é caracterizado pela existência de um único órgão de administração na empresa - o Conselho de Administração - e um Conselho Fiscal e o segundo, pela presença de dois órgãos com responsabilidade administrativa - a Direcção e o Conselho Geral - para além de um Revisor Oficial de Contas. Deste modo, no sistema dualista há uma clara separação da gestão quotidiana da empresa (Direcção) da gestão estratégica (Conselho Geral). No caso da estrutura monista também é usual esta divisão, pois, frequentemente, o Conselho de Administração delega poderes da gestão corrente da empresa sobre uma Comissão Executiva, criada e supervisionada por ele e constituída exclusivamente por administradores

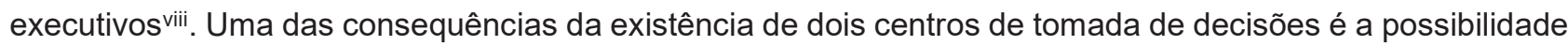
dos respectivos presidentes serem pessoas distintas. No entanto, no sistema monista, isto nem sempre acontece, dando origem à dualidade do CEO'ix.

De acordo com a ideia anterior, a maioria dos investigadores defende que a dualidade do CEO não favorece os interesses dos accionistas. De facto, se tivermos presente que a função do Conselho é garantir que os CEOs e os outros gestores desempenham as suas tarefas de acordo com os interesses dos accionistas (O'SULLIVAN, 2000), no caso de um CEO ser também Presidente do Conselho, facilmente constatamos que este enfrenta "uma situação de potencial conflito de interesse no exercício dessas funções" 
(CONYON; PECK, 1998, p. 149). Assim sendo, Boyd (1994) defende que a avaliação objectiva do CEO e do desempenho da equipa de gestão é mais facilmente alcançada através de um Presidente independentex.

Em contraste, os defensores da dualidade do CEO alegam que esta estabelece linhas bem definidas de autoridade e responsabilidade e cria uma unidade de comando, capaz de reduzir os conflitos de papéis entre os diferentes gestores e melhorar a tomada de decisão (RHOADES et al., 2001). Além disso, esta pode ser utilizada pelo Conselho para fazer transparecer aos diversos stakeholders a noção de que a empresa tem um "sentido claro de direcção" (FINKELSTEIN; D'AVENI, 1994, p. 1084).

No que concerne aos resultados empíricos, KREN e KERR (1997) mostram que quando a mesma pessoa detém os cargos de CEO e de Presidente, o Conselho tem, tendencialmente, mais administradores não executivos, enquanto O'Sullivan (2000) descobre que a presença da dualidade do CEO tem um impacto negativo sobre a representação dos não executivos. Isto sugere que o aumento do poder concedido ao CEO, que também é Presidente do Conselho, está associado a uma quebra na capacidade dos accionistas para nomear mais administradores não executivos e, consequentemente, a um enfraquecimento do controlo do Conselho (O'SULLIVAN, 2000).

\section{Impacto da Representação dos Administradores Não Executivos em Variáveis-Chave da Empresa}

Remuneração dos gestores

$\mathrm{Na}$ última década tem havido um aumento do interesse sobre a remuneração dos gestores como consequência do seu crescimento exponencial e do envolvimento de diversos administradores em alguns escândalos empresariais. O valor e o modo como o pagamento é definido tem estado no centro das atenções (BEBCHUK e FRIED, 2003; BEBCHUCK et al, 2009; CONYON e MURPHY, 2000; HALL e LIEBMAN, 1998).

Alguns autores têm atribuído ao Conselho de Administração da empresa o papel de principal mecanismo interno responsável por determinar a remuneração dos executivos e o controlo da gestão, entre eles, BAYSINGER e HOSKISSON (1990), BOYD (1994), CONYON e PECK (1998), FINKELSTEIN e HAMBRICK (1996) e ZAJAC e WESTPHAL (1994). Neste sentido, o relatório Cadbury Committee (Cadbury) (1992) afirma que devem existir comissões de remuneração, nomeadas pelos Conselhos e constituídas total ou principalmente por administradores não executivos, para a deliberação sobre a determinação do pagamento da gestão de topo, de modo a que os administradores executivos não participem nas decisões sobre a sua própria remuneração.

Deve-se, antes de mais, esclarecer que esta remuneração do Conselho de Administração inclui a remuneração dos membros executivos e a remuneração dos membros não executivos, englobando as suas componentes fixa e variável para cada tipo de membro da administraçãoxi.

Com o objectivo de aumentar a transparência e a independência das comissões de compensação, vários organismos têm introduzido orientações a este respeito. Por exemplo, no domínio jurídico português, salienta-se o Regulamento n. $1 / 2010$ da Comissão do Mercado de Valores Mobiliários (CMVM) que, na alínea a) do seu artigo $3^{\circ}$, estabeleceu que as remunerações dos administradores devem ser divulgadas de forma agregada e individual. 
Diversos estudos testaram se a percentagem de administradores não executivos influencia a remuneração da gestão de topo, através de um forte controlo do Conselho. Mais uma vez os resultados são mistos. Se por um lado, Boyd (1994), Brickley e James (1987) e Mayers et al. (1997) relatam uma relação negativa entre a percentagem de administradores não executivos e a remuneração da gestão, suportando a noção de que os administradores não executivos perseguem os interesses dos accionistas, por outro, Cohen e Lauterbach (2008), Core et al. (1999), Cosh e Hughes (1997) e Fernandes (2008) mencionam uma relação positiva, contrariando as expectativas que se baseiam na teoria da agência. Existem, ainda, autores que indicam que os administradores não executivos não desempenham qualquer papel na determinação da compensação, como é o caso de Conyon e Peck (1998) e Nascimento (2009).

\section{Desempenho da empresa}

As consecutivas falências de grandes empresas têm sido um dos factores que está na origem do aumento do interesse dos investigadores pelas questões relacionadas com o papel de controlo dos administradores não executivos. A forma mais usual para analisar a sua eficácia é relacionar a composição do Conselho com o desempenho da empresa. Para mensurar a variável do desempenho organizacional, a literatura tem utilizado dois tipos de medidas: medidas contabilísticas e medidas baseadas no mercado. Segundo Rhoades et al. (2001), as principais medidas contabilísticas de desempenho utilizadas na literatura são a Rendibilidade do Capital Próprio (ROE) e a Rendibilidade do Activo (ROA). Quanto às medidas baseadas no mercado, os investigadores têm recorrido à rendibilidade anual das acções da empresa (por exemplo, Fernandes (2008) e Kren e Kerr (1997) $)^{\text {xii }}$.

Os trabalhos realizados apresentam diversas conclusões. Enquanto Daily e Dalton (1993) e Pearce e Zahra (1992) identificaram um efeito positivo da percentagem de administradores não executivos sobre o desempenho da empresa, Bhagat e Black (2002) constataram que as empresas com maior número de administradores não executivos apresentaram uma redução significativa no seu desempenho financeiro e de mercado. Outras pesquisas não encontraram uma relação significativa entre a composição do Conselho e o desempenho da empresa (por exemplo, Kren e Kerr (1997) e Dulewicz e Herbert (2004) para o Reino Unido).

Perante estes resultados, Bathala e Rao (1995), Heslin e Donaldson (1999), Long et al. (2005) e Walsh e Seward (1990) indicam que o facto do desempenho da empresa poder depender de outros factores, muitas vezes não identificáveis, que não estão no âmbito do controlo dos gestores é uma possível razão para que existam estudos incapazes de apresentar uma relação directa com a composição do Conselho de Administração. 


\section{METODOLOGIA E FORMULAÇÃO DE HIPÓTESES}

Com o intuito de compreender quais os factores susceptíveis de influenciar a composição do Conselho de Administração, foram desenvolvidas algumas hipóteses com base na revisão da literatura e que relacionam a percentagem de administradores não executivos com a dimensão da empresa, a sua estrutura accionista e a existência (ou não) da dualidade do CEO. Foram, também, incluídas no modelo teórico outras variáveis explicativas que a literatura sugere como úteis para explicar as variações na composição do Conselho, sendo elas: a pertença ao PSI20 (índice bolsista da Euronext Lisbon), o sector de actividade, a permanência/duração no cargo de CEO e a dimensão do Conselho (medida pelo número de administradores). Deste modo, delinearam-se as seguintes hipóteses:

Hipótese 1: Uma maior dimensão da empresa está associada a um maior número de não executivos no Conselho de Administração.

Hipótese 2: O grau de concentração de propriedade tem uma relação inversa com a percentagem de administradores não executivos.

Hipótese 3: A dualidade do CEO tem um impacto negativo sobre a representação de administradores não executivos no Conselho de Administração.

Hipótese 4: As empresas que pertencem ao principal índice português (PSI20) apresentam uma estrutura de administração com mais administradores não executivos.

Hipótese 5: O sector de actividade exerce uma influência significativa na composição do Conselho.

Hipótese 6: Quanto mais tempo o CEO ocupa este cargo menor será o número de administradores não executivos representados no Conselho de Administração.

Hipótese 7: A dimensão do Conselho é um mecanismo de controlo que tem um efeito significativamente positivo sobre a composição do Conselho.

A análise procurou, ainda, explicar a influência da composição do Conselho de Administração sobre duas variáveis importantes para a empresa: o nível de remuneração praticada e o desempenho das empresas cotadas na Euronext Lisbon. Assim, surgem:

Hipótese 8: A percentagem de administradores não executivos no Conselho de Administração afecta negativamente a remuneração dos administradores.

Hipótese 9: A presença de administradores não executivos no Conselho de Administração tem um efeito positivo no ROA e ROE da empresa. 


\section{ANÁLISE EMPÍRICA}

\section{Análise da Amostra}

A amostra do estudo é composta por todas as 40 empresas cotadas na Euronext Lisbon no período entre 2006 e 2009, tendo os dados sido obtidos, principalmente, a partir dos relatórios anuais das empresas e dos respectivos relatórios de governo da sociedade, assim como na base de dados financeira Datastream.

A capitalização de mercado total das 40 empresas e, consequentemente, do mercado da Euronext Lisbon é, em média, de 69.453.746 mil euros. Distinguindo as empresas financeiras das dos restantes sectores, a capitalização média das empresas financeiras da amostra é de 3.413 .555 euros (empregando um $n^{\circ}$ médio de 9.042 trabalhadores), enquanto para as não financeiras esses valores são de, respetivamente, 1.496.742 euros e 6.015 trabalhadores.

A Tabela 1 mostra que, em média, as empresas têm 9,6 membros no Conselho de Administração, sendo 4,89 executivos e 4,71 não executivos. Note-se ainda que existem 3 empresas que permanecem sem qualquer administrador não executivo ao longo dos quatro anos da amostra. A percentagem máxima de administradores não executivos foi de $80,95 \%$. Estes números não parecem estar de acordo com o nível desejado de representação de administradores não executivos, pois indicam que os Conselhos têm, em média, uma maioria de executivos (58,22\% contra $41,78 \%$ de não executivos). Relativamente à dimensão do Conselho verifica-se que à medida que a dimensão da empresa aumenta, a dimensão do Conselho segue a mesma tendência. Apesar deste aumento se verificar tanto em termos de administradores executivos como em termos de não executivos, esta evidência é ainda mais clara no caso dos administradores não executivos - as pequenas empresas têm, em média, cerca de 1 administrador não executivo enquanto as grandes empresas têm aproximadamente 10 .

Relativamente a outros indicadores da amostra (que é constituída, como já se referiu, pelo universo das empresas cotadas na Euronext Lisbon), em média, metade integra o principal índice bolsista português (PSI 20), 54,38\% tem o mesmo indivíduo a ocupar os cargos de CEO e de Presidente do Conselho e o CEO ocupa esta posição há cerca de 12 anos, o que demonstra a quão elevada é a sua influência nestas empresas. O sector das Telecomunicações é o que arrecada maior número de empresas, mas são as empresas do sector da Distribuição que possuem a percentagem mais elevada de administradores não executivos.

As Tabelas 2 e 3 fornecem um panorama geral das práticas de remuneração das empresas cotadas na Euronext Lisbon. Pela tabela 2 verifica-se que a remuneração média anual per capita dos administradores do Conselho de Administração é de 295,56 mil euros (494,59 mil euros para os executivos e 100,64 mil euros para os não executivos). Uma vez que os restantes trabalhadores da empresa auferem, em média, 34,41 mil euros anuais per capita, é possível concluir que os administradores executivos e não executivos ganham 14,38 e 2,92 vezes mais, respectivamente, do que os outros colaboradores. No total, o montante pago aos membros do Conselho de Administração corresponde a 16,26\% do Resultado Líquido da empresa. As grandes empresas bem como as empresas que pertencem ao PSI20 são as que melhor remuneram os seus administradores, mas esta diferença torna-se ainda maior se considerarmos apenas os administradores executivos. Em média, um administrador de uma grande empresa recebe 512,6 mil euros (981,1 mil euros no caso dos executivos) enquanto numa pequena empresa esse administrador receberia 152,64 mil euros (216,51 mil euros no caso referido). A tabela 3 mostra que, no período em análise, a componente fixa, em 
média, representa $69,43 \%$ da remuneração total dos administradores, ao passo que a componente variável soma $30,57 \%$. Denota-se, também, através da Tabela 3, que a componente fixa da remuneração tem uma maior expressão nas empresas que não aderiram ao PSI20 $(83,93 \%)$ e nas empresas de menor dimensão $(90,99 \%)$.

Esta tabela (Tabela 1) apresenta o número médio de administradores que estão presentes no Conselho de Administração, incluindo a sua composição (executivos versus não executivos) e tendo em conta a dimensão da empresa. As empresas da amostra foram divididas em três categorias de dimensão de acordo com a mediana da sua capitalização de mercado, à semelhança de Fernandes (2008). Deste modo, "Grande" são as $20 \%$ maiores empresas, "Pequena" são as $20 \%$ empresas de menor dimensão e "Média" são as restantes empresas. O peso do número de cada tipo de administrador relativamente ao número total de administradores também é apresentado. Os valores aqui presentes são valores médios para o período 20062009.

Tabela 1: Dimensão e Composição do Conselho de Administração (média 2006-2009)

\begin{tabular}{lccccc}
\hline \multirow{2}{*}{ Dimensão da empresa } & \multicolumn{2}{c}{$\begin{array}{c}\text { Administradores } \\
\text { executivos }\end{array}$} & $\begin{array}{c}\text { Administradores não } \\
\text { executivos }\end{array}$ & $\begin{array}{c}\text { Total de } \\
\text { administradores }\end{array}$ \\
\cline { 2 - 6 } & $\mathrm{N}^{\circ}$ & $\%$ & $\mathrm{~N}^{\circ}$ & $\%$ & $\mathrm{~N}^{\circ}$ \\
\hline Grande & 7,22 & $47,74 \%$ & 10,16 & $52,26 \%$ & 17,38 \\
Média & 4,60 & $57,28 \%$ & 4,02 & $42,72 \%$ & 8,63 \\
Pequena & 3,44 & $71,53 \%$ & 1,32 & $28,47 \%$ & 4,76 \\
\hline Total & $\mathbf{4 , 8 9}$ & $\mathbf{5 8 , 2 2 \%}$ & $\mathbf{4 , 7 1}$ & $\mathbf{4 1 , 7 8 \%}$ & $\mathbf{9 , 6 0}$
\end{tabular}

Fonte: dados da pesquisa.

A Tabela 2 apresenta os montantes pagos anualmente, em média, aos administradores executivos e não executivos em termos per capita, fazendo a distinção entre as empresas que integram o PSI20 e as restantes e tendo em conta a sua dimensão. As empresas da amostra foram divididas em três categorias de dimensão de acordo com a mediana da sua capitalização de mercado, à semelhança de Fernandes (2008). Deste modo, "Grande" são as $20 \%$ maiores empresas, "Pequena" são as $20 \%$ empresas de menor dimensão e "Média" são as restantes empresas. Os valores aqui presentes são valores médios para o período 20062009 e expressos em milhares de euros.

Tabela 2: Remuneração anual per capita dos administradores (média 2006-2009)

\begin{tabular}{l|ccc|ccc}
\hline \multicolumn{1}{c|}{ Classificação } & PSI20 & Não PSI20 & Total & Grande & Média & Pequena \\
\hline Executivos & 715,21 & 273,96 & 494,59 & 981,10 & 425,11 & 216,51 \\
Não executivos & 144,58 & 54,25 & 100,64 & 102,05 & 122,58 & 14,63 \\
\hline Total & 410,06 & 181,06 & 295,56 & 512,60 & 270,85 & 152,64 \\
\hline
\end{tabular}

Fonte: dados da pesquisa. 
A Tabela 3 apresenta o peso que cada componente (fixa e variável) tem sobre a remuneração total dos administradores do Conselho de Administração, fazendo a distinção entre as empresas que integram o PSI20 e as restantes e tendo em conta a sua dimensão. As empresas da amostra foram divididas em três categorias de dimensão de acordo com a mediana da sua capitalização de mercado, à semelhança de Fernandes (2008). Deste modo, "Grande" são as $20 \%$ maiores empresas, "Pequena" são as $20 \%$ empresas de menor dimensão e "Média" são as restantes empresas. Os valores aqui presentes são valores médios para o período 2006-2009.

Tabela 3: Componentes da remuneração dos administradores (média 2006-2009)

\begin{tabular}{l|ccc|ccc}
\hline Remuneração & PSI20 & Não PSI20 & Total & Grande & Média & Pequena \\
\hline Fixa & $54,93 \%$ & $83,93 \%$ & $69,43 \%$ & $53,43 \%$ & $67,41 \%$ & $90,99 \%$ \\
Variável & $45,07 \%$ & $16,07 \%$ & $30,57 \%$ & $46,56 \%$ & $32,59 \%$ & $9,01 \%$ \\
\hline
\end{tabular}

Fonte: dados da pesquisa.

\section{Definição do Modelo}

Como forma de avaliar a influência de um conjunto de variáveis sobre a representação dos administradores não executivos nos Conselhos de Administração das empresas cotadas, definiu-se o seguinte modelo teórico:

$$
\begin{aligned}
& \% \text { Não executivos }{ }_{i, t}=\beta_{0}+\beta_{1} \text { Dimensão empresa }_{i t} \\
& +\beta_{2} \text { Estrutura accionista }{ }_{i t}+\beta_{3} \text { Dualidade CEO }{ }_{i t} \\
& +\beta_{4} \text { Adesão PSI20 }{ }_{i t}+\beta_{5} \text { Distribuição }_{i t}+\beta_{6} \text { Construção }_{i t} \\
& +\beta_{7} \text { Telecom }_{i t}+\beta_{8} \text { Indústria }_{i t}+\beta_{9} \text { ServFianc }_{i t}+\beta_{10} \text { ElectGseRe }_{i t} \\
& +\beta_{11} \text { Duração cargo }_{i t}+\beta_{12} \text { Dimensão Conselho }_{i t}+\varepsilon_{i t} \text {, } \\
& t=2006, \ldots, 2009
\end{aligned}
$$

onde \% Não executivos $i t$ é a variável dependente e representa a percentagem de administradores não executivos utilizada pela empresa $i$ no ano $t$.

Relativamente às variáveis explicativas, e na sequência da revisão de literatura, a dimensão da empresa será controlada pelo número de empregados, total do activo, vendas e prestações de serviços (ou produto bancário $)^{\text {xiii }}$ e capitalização de mercado. A Estrutura accionista diz respeito à percentagem do número total de acções detidas pelos dois ou pelos quatro maiores accionistas da empresa (índice de concentração absoluta $\mathrm{C}_{2}$ e $\mathrm{C}_{4}$ ). As variáveis Dualidade CEO e Adesão PSI20 são duas variáveis dummies. No primeiro caso, a variável assume o valor "1" se o CEO é também Presidente do Conselho de Administração e "0", se tal não se verifica. No segundo caso, a variável é igual a "1" se a empresa pertence ao principal índice português (PSI20) e "0", caso contrário. Para avaliar a influência do sector de actividade na composição do Conselho foram utilizadas seis variáveis dummies - Distribuição, Construção, Telecom (Telecomunicações), Indústria, ServFinanc (Serviços Financeiros) e ElectGseRe (Electricidade, Gás e Retalho), cada uma a representar o sector onde a empresa exerce a sua actividade. Duração cargo refere-se ao tempo que o CEO 
detém esta posição na empresa e a Dimensão Conselho é o número de administradores no Conselho. Relativamente aos parâmetros, $\beta_{0}$ é uma constante e $\beta_{1}, \beta_{2}, \ldots, \beta_{13}$ são os coeficientes associados às respectivas variáveis explicativas. $\varepsilon_{i t}$ é o erro ou resíduo do modelo e representa os factores não observados que mudam ao longo do tempo e afectam a variável dependente (WOOLDRIDGE, 2010).

Adicionalmente, analisou-se o impacto que a percentagem de administradores não executivos tem sobre as seguintes variáveis: remuneração total dos administradores, remuneração dos executivos e desempenho da empresa. Para o efeito, estimaram-se os seguintes modelos, respectivamente:

Remuneração total $_{i t}=\beta_{0}+\beta_{1} \%$ Não executivos ${ }_{i t}+\varepsilon_{i t}$

$$
t=2006, \ldots, 2009
$$

Remuneração executivos $_{i t}=\beta_{0}+\beta_{1} \%$ Não executivos ${ }_{i t}+\varepsilon_{i t}$,

$$
t=2006, \ldots, 2009
$$

Desempenho empresa $_{i t}=\beta_{0}+\beta_{1} \%$ Não executivos ${ }_{i t}+\varepsilon_{i t}$,

$$
t=2006, \ldots, 2009
$$

A remuneração total dos administradores num determinado ano foi definida como a soma dos seus salários (parte fixa) e de uma componente variável. O desempenho da empresa é representado pela rendibilidade do activo e pela rendibilidade do capital próprio. Mais uma vez, $\beta_{0}$ é uma constante e $\beta_{1}$ é o coeficiente associado à variável \% Não executivos ${ }_{i t}$. $\mathcal{E}_{i t}$ é o erro ou resíduo do modelo.

\section{Estimação e Análise dos Resultados}

Atendendo às características do estudo, recorreu-se à estimação dos parâmetros com base em modelos econométricos para dados de painel. Efectivamente os dados de painel caracterizam-se por terem tanto a dimensão de uma série transversal como de uma série temporal (no nosso caso, indicadores de 40 empresas para 4 anos) e têm sido cada vez mais utilizados em pesquisas empíricas (WOOLDRIDGE, 2010). O modelo (4.1) foi estimado segundo dois métodos: Random Effects (RE) e Fixed Effects (FE) mas tendo em atenção as características do modelo teórico e os resultados do teste de Hausmann, são apenas analisados os resultados alcançados através dos random effects (WOOLDRIDGE, 2010). Note-se, ainda, que se estimou o modelo (4.1) separadamente para as diferentes variáveis representativas da dimensão e da estrutura accionista da empresa ${ }^{\text {xiv. }}$.

A Tabela 4 apresenta os resultados do modelo (4.1) onde a variável dependente é a \% não executivos presente no Conselho de Administração da empresa $i$ e as variáveis independentes são a dimensão da empresa (totalactivo), assim como um conjunto de variáveis associadas à estrutura accionista da empresa $\left(\mathrm{C}_{2}\right.$ e $\mathrm{C}_{4}$ ), à influência do CEO (dualidade CEO e duração cargo), ao facto da empresa pertencer ao PSI20 (adesão PS/20), ao sector de actividade onde está inserida (distribuição, construção, telecom, indústria, servfinanc, electgsere) e à dimensão do Conselho (dimensão Conselho). Aqui são apresentadas as estimativas para os coeficientes de cada regressor e os respectivos p-values, assim como indicadores da qualidade global dos resultados obtidos (valor do $R^{2}$ e do teste de Wald/F). Nas colunas (1) e (2) as estimativas 
foram obtidas através do método dos efeitos aleatórios: no modelo (1) utilizou-se a variável $\mathrm{C}_{2}$ para representar a estrutura accionista da empresa, enquanto no modelo (2) esta é caracterizada pela variável $\mathrm{C}_{4}$.

Tabela 4: Resultados da estimação do modelo (4.1) utilizando a variável totalactivo

\begin{tabular}{|c|c|c|c|c|}
\hline \multirow{3}{*}{ Regressores } & \multicolumn{2}{|c|}{ Modelo (4.1) } & \multicolumn{2}{|c|}{ Modelo (4.1) } \\
\hline & \multicolumn{2}{|c|}{$(1)$} & \multicolumn{2}{|l|}{ (2) } \\
\hline & Coeficiente & $p$-value & Coeficiente & $p$-value \\
\hline Totalactivo & $-2,91 \mathrm{E}^{-09}$ & 0,159 & $-2,71 \mathrm{E}^{-09}$ & 0,194 \\
\hline $\mathrm{C}_{2}$ & $-0,0919$ & 0,449 & & \\
\hline $\mathrm{C}_{4}$ & & & $-0,0485$ & 0,712 \\
\hline dualidade CEO & $-0,1104$ & 0,003 & $-0,1080$ & 0,004 \\
\hline adesão PSI20 & $-0,1439$ & 0,072 & $-0,1408$ & 0,085 \\
\hline Distribuição & 0,2624 & 0,114 & 0,2650 & 0,116 \\
\hline Construção & 0,0460 & 0,714 & 0,0523 & 0,681 \\
\hline Telecom & 0,0230 & 0,833 & 0,0353 & 0,749 \\
\hline Indústria & 0,1264 & 0,308 & 0,1388 & 0,265 \\
\hline Servfinanc & $-0,1270$ & 0,383 & $-0,1257$ & 0,394 \\
\hline Electgsere & 0,0264 & 0,849 & 0,0310 & 0,825 \\
\hline duração cargo & 0,0009 & 0,740 & 0,0011 & 0,666 \\
\hline dimensão Conselho & 0,0364 & 0,000 & 0,0365 & 0,000 \\
\hline Constante & 0,2421 & 0,095 & 0,2057 & 0,187 \\
\hline $\mathrm{R}^{2}$ within & 0,4910 & & 0,491 & \\
\hline$R^{2}$ between & 0,5484 & & 0,539 & \\
\hline $\mathrm{R}^{2}$ overall & 0,5317 & & 0,527 & \\
\hline Wald/F & 114,27 & & 113,3 & \\
\hline$p$-value Wald/F & 0,0000 & & 0,000 & \\
\hline
\end{tabular}

Fonte: dados da pesquisa.

Não foram encontrados suportes empíricos para a Hipótese 1 - à semelhança de Bathala e Rao (1995) e Kren e Kerr (1997), verifica-se que a dimensão da empresa não está estatisticamente relacionada com a percentagem de não executivos. A falta de significância poderá significar que, actualmente, estas empresas estão a optar por dar maior ênfase a outros mecanismos de governo, tal como a posse de acções por parte da gestão. Por exemplo, Jensen e Meckling (1976) argumentam que quando a gestão detém acções da empresa, os interesses dos gestores e dos accionistas tornam-se mais alinhados, não havendo necessidade de recrutar mais administradores não executivos.

Ao contrário do que foi observado em pesquisas anteriores, estes resultados mostram que a estrutura de propriedade não tem qualquer influência sobre a composição do Conselho, não se podendo, por isso, confirmar a Hipótese 2. Isto parece inconsistente com a noção de que a concentração de propriedade é um mecanismo de controlo substituto dos administradores não executivos, uma vez que os grandes accionistas 
têm uma capacidade de controlo que os pequenos accionistas não têm quando a propriedade se encontra dispersa.

A dualidade do CEO surge na literatura como um indicador do elevado poder desfrutado pelo CEO em relação aos outros membros do Conselho (BOYD, 1994; FINKELSTEIN; HAMBRICK, 1996). Os resultados confirmam esta expectativa, expressa na Hipótese 3. Na amostra, em média, uma empresa onde o CEO e o Presidente são a mesma pessoa tem menos administradores não executivos do que uma empresa onde estes cargos são exercidos por pessoas diferentes. Isto sugere que o CEO que também é Presidente utiliza a sua influência para impedir a admissão de mais administradores não executivos.

Existem, ainda, outras variáveis de controlo que também apresentam efeitos significativos sobre a composição do Conselho. A dimensão do Conselho é um desses casos. Quanto mais administradores o Conselho possuir, maior é a percentagem referente aos administradores não executivos, dando suporte à hipótese 7. Relativamente às empresas que pertencem ao principal índice português, apesar da sua elevada visibilidade e prestígio, têm menos administradores não executivos no board do que as restantes. Este resultado não permite aceitar a hipótese delineada anteriormente (Hipótese 4).

Houve também uma relação significativa entre a proporção de não executivos e os sectores da distribuição e dos serviços financeiros quando o número de empregados ou as vendas e prestações de serviços $^{x v}$ são utilizados para caracterizar a dimensão da empresa. No entanto, estas relações têm o sentido inverso, ou seja, se uma empresa exerce a sua actividade no sector da distribuição esta percentagem, em média, aumenta. Todavia, se a atenção recair sobre o sector financeiro, o impacto é negativoxvi. Todas as outras variáveis (e nomeadamente a duração de permanência no cargo) não desempenham qualquer papel significativo na definição da proporção de membros não executivos nos Conselhos de Administração.

De seguida, a análise testou se a percentagem de não executivos é determinante para a remuneração dos administradores em geral e dos executivos em particular. Os resultados da estimação de (4.2) e (4.3) estão disponíveis nas Tabelas 5 e 6 . Estes outputs indicam que a percentagem de administradores não executivos tem uma relação positiva tanto com a remuneração total dos administradores como com a dos executivos. Isto é consistente com estudos anteriores sobre a remuneração dos administradores (por exemplo, Cohen e Lauterbach (2008), Core et al. (1999), Cosh e Hughes (1997) e Fernandes (2008)). Contudo, estes resultados não corroboram a hipótese descrita anteriormente (Hipótese 5). Existe, assim, evidência estatística de que os não executivos não estão a cumprir adequadamente o seu papel de controlo no que diz respeito às remunerações do board. Acerca disto, Boyd (1994) nota que os altos níveis de remuneração comprometem a eficácia dos administradores, pondo-a em causa. 
A Tabela 5 apresenta os resultados do modelo (4.2) onde a variável dependente é a remuneração total dos administradores do Conselho de Administração da empresa $i$ e a variável independente é a \% não executivos. São apresentadas as estimativas obtidas pelos random effects para os coeficientes de cada regressor e os respectivos $p$-values, assim como indicadores da qualidade global dos resultados obtidos $\left(R^{2}\right.$ e do teste de Wald/F).

Tabela 5: Resultados da estimação do modelo (4.2)

\begin{tabular}{lcc}
\hline \multirow{2}{*}{ Regressores } & \multicolumn{2}{c}{ Modelo (4.2) } \\
\cline { 2 - 3 } & Coeficiente & $\boldsymbol{p}$-value \\
\hline \% não executivos & 3596,252 & 0,006 \\
Constante & 1713,181 & 0,019 \\
\hline $\mathrm{R}^{2}$ within & 0,0444 \\
$\mathrm{R}^{2}$ between & 0,0565 \\
$\mathrm{R}^{2}$ overall & 0,0507 \\
\hline Wald/F & \multicolumn{2}{c}{7,64} \\
$p$-value Wald/F & \multicolumn{3}{c}{0,0057} \\
\hline
\end{tabular}

Fonte: dados da pesquisa.

$\mathrm{Na}$ Tabela 6 são apresentados os resultados do modelo (4.3) onde a variável dependente é a remuneração total dos administradores executivos do Conselho de Administração da empresa $i$ e a variável independente é a \% não executivos. Aqui são apresentadas as estimativas obtidas pelos random effects para os coeficientes de cada regressor e os respectivos $p$-values, assim como indicadores da qualidade global dos resultados obtidos (valor do $\mathrm{R}^{2}$ e do teste de Wald/F).

Tabela 6: Resultados da estimação do modelo (4.3)

\begin{tabular}{lcc}
\hline \multirow{2}{*}{ Regressores } & \multicolumn{2}{c}{ Modelo (4.3) } \\
\cline { 2 - 3 } & Coeficiente & p-value \\
\hline \% não executivos & $2.755,88$ & 0,026 \\
constante & $1.604,027$ & 0,018 \\
\hline $\mathrm{R}^{2}$ within & \multicolumn{2}{c}{0,0373} \\
$\mathrm{R}^{2}$ between & 0,0226 \\
$\mathrm{R}^{2}$ overall & \multicolumn{2}{c}{0,0234} \\
\hline Wald/F & \multicolumn{3}{c}{4,93} \\
$p$-value Wald/F & \multicolumn{2}{c}{0,0265} \\
\hline
\end{tabular}

Fonte: dados da pesquisa 
Para estudar o impacto da percentagem de administradores não executivos no desempenho da empresa foi estimada a equação (4.4). A partir da Tabela 7, constata-se que a percentagem de não executivos explica a variação ocorrida no desempenho da empresa apenas quando o ROE é utilizado como variável dependente. Contrariando a hipótese 9, estes resultados indicam que quando esta percentagem aumenta existe destruição do valor para o acionista quando medido pelo ROE. Em estudos semelhantes a este, Bhagat e Black (2002) e Fernandes (2008) mostram que as empresas com mais administradores não executivos não apresentam um melhor desempenho comparativamente com as outras.

A Tabela 7 apresenta os resultados do modelo (4.4) onde a variável dependente é a rendibilidade do activo $(R O A)$ da empresa $i$ ou a rendabilidade do capital próprio (ROE) e a variável independente é a \% não executivos. Aqui são apresentadas as estimativas obtidas pelo método dos random effects para os coeficientes de cada regressor e os respectivos $p$-values, assim como indicadores da qualidade global dos resultados obtidos (valor do $\mathrm{R}^{2}$ e do teste de Wald/F).

Tabela 7: Resultados da estimação do modelo (4.4) utilizando a variável ROA

\begin{tabular}{|c|c|c|c|c|}
\hline \multirow{3}{*}{ Regressores } & \multirow{2}{*}{\multicolumn{2}{|c|}{$\begin{array}{c}\text { Modelo (4.4) } \\
\text { (ROA) }\end{array}$}} & \multirow{2}{*}{\multicolumn{2}{|c|}{$\begin{array}{c}\text { Modelo (4.4) } \\
\text { (ROE) }\end{array}$}} \\
\hline & & & & \\
\hline & Coeficiente & p-value & Coeficiente & $p$-value \\
\hline \% não executivos & $-0,0031$ & 0,892 & $-1,6534$ & 0,029 \\
\hline constante & 0,0399 & 0,001 & 1,0479 & 0,004 \\
\hline $\mathrm{R}^{2}$ within & \multicolumn{2}{|c|}{0,0268} & \multicolumn{2}{|c|}{0,000} \\
\hline$R^{2}$ between & \multicolumn{2}{|c|}{0,1075} & \multicolumn{2}{|c|}{0,1499} \\
\hline $\mathrm{R}^{2}$ overall & \multicolumn{2}{|c|}{0,0301} & \multicolumn{2}{|c|}{0,0296} \\
\hline Wald/F & \multicolumn{2}{|c|}{0,02} & \multicolumn{2}{|c|}{4,76} \\
\hline$p$-value Wald/F & \multicolumn{2}{|c|}{0,8924} & \multicolumn{2}{|c|}{0,0294} \\
\hline
\end{tabular}

Fonte: dados da pesquisa.

Em síntese, os principais resultados obtidos revelam que a dimensão da empresa não tem influência no grau de representação de administradores não executivos, assim como a concentração de propriedade. A dualidade do CEO apresenta um efeito negativo sobre a composição do Conselho, o que corrobora a noção de que para um maior controlo da gestão, as empresas devem ter um CEO diferente do Presidente do Conselho de Administração. Verificaram-se, ainda, fortes indícios da existência de uma relação significativa entre a adesão ao PSI20 e a percentagem de não executivos, embora sendo negativa. A dimensão do Conselho apresenta uma significância estatística positiva, o que significa que, quando o Conselho é constituído por um maior número de administradores, a proporção que corresponde aos não executivos aumenta. Por último, das restantes variáveis introduzidas no modelo, somente os sectores da distribuição e financeiro têm alguma relevância estatística.

Contrariamente às recomendações da CMVM, são os Conselhos de Administração com mais administradores não executivos que apresentam níveis remuneratórios mais elevados. Obteve-se, ainda, evidência mista sobre o desempenho da empresa, ou seja, por um lado, a percentagem de não executivos 
influencia negativamente o ROE das empresas da amostra, mas, por outro, não tem qualquer relação com o ROA.

\section{CONCLUSÕES}

Este trabalho estudou as questões associadas aos administradores não executivos das empresas cotadas na Euronext Lisbon, analisando os determinantes da composição do Conselho de Administração, assim como o papel desempenhado por estes administradores na mediação dos interesses entre accionistas e gestores.

Os resultados apresentados são interessantes e obrigam a repensar alguns pressupostos considerados ao longo do trabalho, pois à semelhança de Fernandes (2008), constatou-se que o papel de controlo atribuído aos administradores não executivos não parece estar a ser cumprido.

Contudo, toda esta análise está sujeita a algumas limitações que decorrem de se ter estudado um mercado de capitais com um reduzido número de empresas cotadas (apenas as 40 que foram estudadas), reduzindo a robustez estatística dos resultados. Outras limitações resultam das limitações das medidas de desempenho utilizadas (contabilísticas). Por último, em estudos futuros poderá ser analisado um período mais longo, assim como introduzir outras variáveis relevantes para o estudo (por exemplo, associadas a composição do Conselho de Administração a percentagem de acções detidas pelos não executivos, a sua experiência, nível de escolaridade e a idade).

Espera-se que este trabalho tenha ajudado a compreender mais detalhadamente os determinantes da composição do Conselho de Administração e o papel dos seus membros não executivos no processo de governo e de controlo das empresas. Por outro lado, acredita-se que ele estimulará uma maior reflexão e discussão sobre a problemática do corporate governance. Importa ainda aprofundar esta análise, em linha com as sugestões de Desender et al (2013) e de Aguilera et al (2015), relacionando este mecanismo interno de governance, com alguns dos mecanismos externos (quadro legal, mercado pelo controlo de empresas, auditores externos, dentre outros).

\section{REFERÊNCIAS}

ADAMS R.B. Governance and the financial crisis. International Review of Finance. 2012 v. 12, n.1, p. 7-38, 2012.

AGUILERA, R.V.; DESENDER, K.; BEDNAR M.K.; LEE, J.H. Connecting the dots: Bringing external corporate governance into the corporate governance puzzle. The Academy of Management Annals. v. 9, n. 1, p.483-573, 2015

BATHALA, C. T.; RAO, R. P. The Determinants of Board Composition: An Agency Theory Perspective. Managerial and Decision Economics, v. 16, n. 1, p. 59-69, 1995.

BAYSINGER, B.; HOSKISSON, R. E. The Composition of Board of Directors and Strategic Control: Effects on Corporate Strategy. Academy of Management Review, v. 15, n. 1, p. 72-87, 1990.

BEBCHUK, L. A.; FRIED, J. M. Executive compensation as an Agency Problem. Journal of Economic Perspectives, v. 17, n. 3, p. 71-92, 2003.

BEBCHUK, L. A.; COHEN, A.; FERRELL, A. What Matters in Corporate Governance?. The Review of Financial Studies, Oxford, v. 22, n. 2, p. 783-827, 2009.

BEBCHUK L.A.; WEISBACH M.S. The state of corporate governance research. The Review of Financial Studies. v. $23, \mathrm{n}$. 3, p. $939-61,2010$

BECHT, M.; BOLTON, P.; RÖELL, A. Corporate Governance and Control. Handbook of the Economics of Finance. Vol. 1., p. 1-109. 
BHAGAT, S.; BLACK, B. The non-correlation between board independence and long-term firm performance. Journal of Corporation Law, v. 27 n. 2, p. 231-273, 2002.

BOYD, B. K. Board Control and CEO Compensation. Strategic Management Journal, v. 15, n. 5, p. 335-344, jun. 1994.

BRICKLEY, J. A.; JAMES, C. M. The Takeover Market, Corporate Board Composition and Ownership Structure: The Case of Banking. Journal of Law and Economics, v. 30, n. 1, p. 161-180, abr. 1987.

CADBURY, A. Report of the Committee on the Financial Aspects of Corporate Governance. London: Gee, 1992.

COHEN, S.; LAUTERBACH, B. Differences in pay between owner and non-owner CEOs: Evidence from Israel. Journal of Multinational Financial Management, v. 18, p. 4-15, 2008.

CONYON, M. J.; MURPHY, K. The prince and the pauper? CEO pay in the United States and United Kingdom. Economic Journal, Oxford, v. 110, n. 467, p. 640-671, nov. 2000.

CONYON, M. J.; PECK, S. I. Board Control, Remuneration Committees, and Top Management Compensation. Academy of Management Journal, v. 41, n. 2, p. 146-57, abr. 1998.

CORE, J. E.; HOLTHAUSEN, R. W.; LARCKER, D. F. Corporate governance, chief executive officer compensation, and firm performance. Journal of Financial Economics, Philadelphia, v. 51, p. 371-406, 1999.

$\mathrm{COSH}$, A. D.; HUGHES, A. Executive remuneration, executive dismissal and institutional shareholdings. International Journal of Industrial Organization, Cambridge, v. 15, p. 469-492, 1997.

DAILY, C. M.; DALTON, D. R. Board of directors leadership and structure: Control and performance implications. Entrepreneurship: Theory and Practice, v. 17, n. 3, p. 65-81, 1993.

DESENDER, K.A.; AGUILERA, R.V.; CRESPI, R.;GARCIA-CESTONA, M. When does ownership matter? Board characteristics and behavior. Strategic Management Journal, v. 34, n. 7, p.823-842, 2013.

DULEWICZ, V.; HERBERT, P. Does the composition and practice of boards of directors bear any relationship to the performance of their companies?. Corporate Governance: An International Review, Oxford, v. 12, n. 3, p. 263-280, 2004.

ERKENS, D.H.; HUNG, M.; MATOS, P. Corporate governance in the 2007-2008 financial crisis: Evidence from financial institutions worldwide. Journal of Corporate Finance, v. 18, n. 2, p. 389-411, 2012

FAMA, E. F.; JENSEN, M. C. Separation of Ownership and Control. Journal of Law and Economics, v. 26, n. 2, p. 301325, 1983.

FERNANDES, N. EC: Board compensation and firm performance: The role of "independent" board members. Journal of Multinational Financial Management, v. 18, p. 30-44, 2008.

FINEGOLD, D.; BENSON, G. S.; HECHT, D. Corporate Boards and Company Performance: review of research in light of recent reforms. Corporate Governance: an International Review, v. 15, n. 5, p. 865-878, 2007.

FINKELSTEIN, S.; D'AVENI, R. A. CEO Duality as a Double-Edged Sword: How Boards of Directors Balance Entrenchment Avoidance and Unity of Command. Academy of Management Journal, v. 37, n. 5, p. 1079-1108, 1994.

FINKELSTEIN, S.; HAMBRICK, D. C. Strategic Leadership: Top Executives and their Effects on Organizations. St. Paul: West Publishing Company, 1996.

GUPTA, K. ; KRISHNAMURTI, C. ; TOURANI-RAD, A. (2013). Is corporate governance relevant during the financial crisis?. Journal of International Financial Markets, Institutions and Money, v. 23, p. 85-110, 2013

HALL, B. J.; LIEBMAN, J. B. Are CEOs really paid like bureaucrats?. Quarterly Journal of Economics, v. 113, n. 3, p. 653691, ago. 1998

HAMBRICK, D. C.; FINKELSTEIN, S. The Effects of Ownership Structure on Conditions at the Top: The Case of CEO Pay Raises. Strategic Management Journal, v. 16, n. 3, p. 175-193, mar. 1995.

HELLAND E.; SYKUTA, M. Who's monitoring the monitor? Do outside directors protect shareholders' interests?. Financial Review, v. 40, n. 2, p. 155-72, 2005

HESLIN, P. A.; DONALDSON, L. An Organizational Portfolio Theory of Board Composition. Corporate Governance: an International Review, v. 7, n. 1, p. 81-88, 1999.

HIGGS, D. Review of the role and effectiveness of non-executive directors. London: The Department of Trade and Industry, 2003.

JENSEN, M. C.; MECKLING, W. H. Theory of The Firm: Managerial Behaviour, Agency Costs and Ownership Structure. Journal of Financial Economics, v. 3, p. 305-360, jun. 1976.

JOHNSON, J. L.; DAILY, C. M.; ELLSTRAND, A. E. Boards of Directors: A Review and Research Agenda. Journal of Management, v. 22, n. 3, p. 409-438, 1996.

KIRKPATRICK, G. The corporate governance lessons from the financial crisis. OECD Journal: Financial Market Trends. V. 2009(1), p. 61-87, 2009 
KREN, L.; KERR, J. L. The Effects of Outside Directors and Board Shareholdings on the Relation Between Chief Executive Compensation and Firm Performance. Accounting and Business Research, v. 27, n. 4, p. 297-309, 1997.

LI, J. Ownership Structure and Board Composition: A Multi-Country Test of Agency Theory Predictions. Managerial and Decision Economics: Aspects of Corporate Governance, Honolulu, v. 15, n. 4, p. 359-368, 1994.

LONG, T.; DULEWICZ, V.; GAY, K. The Role of the Non-executive Director: findings of an empirical investigation into the differences between listed and unlisted UK boards. Corporate Governance, v. 13, n. 5, p. 667-679, 2005.

MAYERS, D.; SHIVDASANI, A.; SMITH JR., C. W. Board Composition and Corporate Control: Evidence from the Insurance Industry. The Journal of Business, Chicago, v. 70, n. 1, p. 33-62, 1997

NASCIMENTO, R. P DO. A remuneração dos Administradores e o Desempenho da Empresa: O Caso Português. Cadernos do Mercado de Valores Mobiliários, Lisboa, n. 32, p. 73-93, 2009.

O'SULLIVAN, N. The Determinants of Non-Executive Representation on the Boards of Large UK Companies. Journal of Management and Governance, v. 4, p. 283-297, 2000.

PEARCE, J. H.; ZAHRA, S. A. Board Composition from a Strategic Contingency Perspective. Journal of Management Studies, v. 29, n. 4, p. 411-438, 1992.

PORTUGAL. CÓDIGO DAS SOCIEDADES COMERCIAIS, 2009. Disponível em: <http://legixpt.legix.pt/docs/CSC15_Set_2009.pdf>. Acesso em: 15 jan. 2012.

PORTUGAL. COMISSÃO DO MERCADO DE VALORES MOBILIÁRIOS - CMVM. Regulamento da CMVM n. ${ }^{\circ} 10 / 2005$ (Altera os Regulamentos da CMVM n. ${ }^{\circ}$ 7/2001 e n. ${ }^{\circ}$ 4/2004 relativos ao Governo das Sociedades e a Deveres de Informação), Lisboa, 2005.

PORTUGAL. COMISSÃO DO MERCADO DE VALORES MOBILIÁRIOS - CMVM. Regulamento da CMVM n. ${ }^{\circ} 1 / 2010$ Governo das Sociedades Cotadas, Lisboa, 2010.

REINA, J. M. M. Interación entre Mecanismos Internos y Externos de Gobierno como elemento detonante de la Creacion de valor: un estudio internacional. Revista Brasileira de Gestão de Negócios, São Paulo, v.14, n.43, p.143-158, 2012.

RHOADES, D. L.; RECHNER, P. L.; SUNDARAMURTHY, C. A. Meta-analysis of Board Leadership Structure and Financial Performance: are "two heads better than one"?. Corporate Governance, v. 9, n. 4, p. 311-319, 2001.

SHIVDASANI, A.; YERMACK, D. CEO involvement in the selection of new board members: an empirical analysis. Journal of Finance, v. 54, n. 5, p. 1829-1853, 1999.

SIKKA, P. Financial crisis and the silence of the auditors. Accounting, Organizations and Society. v. 34, n.6-7, p. 868-73, 2009.

SILVA, A.S. ; VITORINO, A; ALVES,C.; CUNHA, J.; MONTEIRO, M.A.Cuet al. Livro Branco sobre Corporate Governance em Portugal. Lisboa: Instituto Português de Corporate Governance, 2006.

SILVA, E. S.; SANTOS, J. F.; ALMEIDA, M. A. Conselho de Administração: uma análise da influência nos níveis de endividamento. Revista Brasileira de Gestão de Negócios, São Paulo, v.13, n.41, p.440-453, 2011.

TOSI, H. L.; GOMEZ-MEJIA, L. R. CEO compensation monitoring and firm performance. Academy of Management Journal, v. 37, n. 4, p. 1002-1016, 1994.

WALSH, J. P.; SEWARD, J. K. On the Efficiency of Internal and External Corporate Control Mechanisms. Academy of Management Review, v. 15, n. 3, p. 421-458, 1990.

WESTPHAL, J. D.; ZAJAC, E. J. Who shall govern? CEO/board power, demographic similarity, and new director selection. Administrative Science Quarterly, v. 40, p. 60-83, 1995.

WOOLDRIDGE, J.M., Econometric analysis of cross section and panel data. MIT Press, 2010

ZAJAC, E. J.; WESTPHAL, J. D. The costs and benefits of managerial incentives and monitoring in the largest U.S. corporations: When is more not better?. Strategic Management Journal, v. 15, p. 121-142, 1994.

\footnotetext{
Segundo FAMA e JENSEN (1983), os conflitos de agência ocorrem porque o autor das decisões (o gestor) não participa no resultado financeiro da empresa e "incluem negligência, consumo excessivo de privilégios, e envolvimento em investimentos que não maximizam o valor para o accionista" (BATHALA; RAO, 1995, p. 59).

ii Segundo KREN e KERR (1997), os administradores executivos são os gestores que são funcionários da empresa a tempo inteiro e os administradores não executivos são os indivíduos que não são funcionários da empresa e que não têm relações familiares com os administradores nem relações financeiras significativas com a organização.

iii Actualmente, a definição de independência vai além da noção tradicional de não executivo versus executivo. "Agora a independência exige que os indivíduos não tenham qualquer relação material com a empresa, ou seja, que eles não sejam funcionários recentes, familiares dos membros, nem façam parte de cargos de chefia interligados" (FINEGOLD et al., 2007, p. 866). Em Portugal, nos termos do n. ${ }^{\circ} 2$ do artigo $1^{\circ}$ do Regulamento 10/2005 da CMVM, "não são considerados administradores não executivos independentes os que estejam associados a quaisquer grupos de interesses específicos na sociedade ou que se encontrem nalguma circunstância susceptível de afectar a sua isenção de análise e de decisão (...)".
} 
iv A elevada remuneração dos administradores não executivos e o facto de não ser necessário muito esforço no desempenho das suas funções contribuem para que não existam incentivos suficientes para estimular estes administradores a agirem de acordo com os interesses dos accionistas, comprometendo, deste modo, a sua independência e credibilidade (BOYD, 1994).

$\checkmark$ A estrutura de propriedade dispersa é caracterizada por ser repartida por um elevado número de accionistas (individuais e institucionais não relacionados), não tendo nenhum deles uma participação dominante (situação mais frequente no modelo anglo-saxónico). No segundo caso, a propriedade das empresas está concentrada num pequeno número de accionistas de referência (empresas directamente relacionadas, bancos e famílias), os quais têm poder para influenciar significativamente as decisões da empresa (situação mais comum na Europa)

vi Isto deve-se ao facto de que à medida que as suas participações aumentam, fica mais caro retirar ou transferir as participações para outras empresas (BATHALA; RAO, 1995; BOYD, 1994) e, por isso, há uma maior dificuldade no trading diário e em "votar com os pés", pelo que estes optam por exercer o activismo institucional de outra forma - através da "voice".

vii O sistema monista impera em Portugal (embora os dois sistemas estejam consagrados no artigo $278^{\circ}$ do Código das Sociedades Comerciais) enquanto o sistema dualista predomina na Alemanha, Áustria, Dinamarca, Holanda e Suíça.

viii Em Portugal, esta matéria encontra-se consagrada no artigo $407^{\circ}$ do Código das Sociedades Comerciais.

ix "A dualidade do CEO existe quando o CEO de uma empresa também actua como Presidente do Conselho de Administração. Manter a posição altamente simbólica de Presidente do Conselho proporcionará ao CEO uma maior base de poder e um lugar de controlo" (BOYD, 1994, p. 338).

x A este propósito, o relatório Cadbury (1992) recomendou que deveria haver uma divisão das responsabilidades na direcção da empresa para que ninguém tenha poderes ilimitados no processo de decisão. Partilhando da mesma opinião, a CMVM entende que nas empresas cotadas é recomendável que as funções de Presidente do Conselho de Administração e de Presidente da Comissão Executiva sejam desempenhadas por pessoas distintas.

xi Segundo FERNANDES (2008, p. 33), a remuneração fixa "consiste numa remuneração mensal, regular e periódica, com uma quantidade invariável, paga durante o ano. A remuneração variável é indexada a um grupo de indicadores financeiros" com o intuito de alinhar os interesses do principal e do agente.

xii A utilização destas tem sido alvo de algumas críticas. As primeiras têm sido acusadas de serem facilmente manipuladas pelos gestores e de poderem não reflectir o real valor da empresa (KREN; KERR, 1997). Relativamente às medidas de desempenho baseadas no mercado, ainda que consideradas mais fortes, por não estarem "sujeitas à manipulação directa da gestão" (RHOADES et al., 2001, p. 313), o facto de os mercados financeiros poderem não ser a principal fonte onde as empresas se financiam dá origem a que os preços das acções não sejam considerados uma medida adequada do desempenho da empresa (FERNANDES, 2008).

xiii No caso do sector financeiro.

xiv Apresenta-se a tabela relativa à estimação tendo como variável de dimensão o total do activo. Podem ser disponibilizadas as estimações relativas às restantes proxies para a dimensão ( $\mathrm{n}^{\circ}$ de empregados, vendas/produto bancário, capitalização bolsista). Notese que não se registam diferenças substanciais na amplitude dos resultados.

xv Ou o produto bancário, no caso do sector financeiro.

xvi Relativamente ao sector financeiro, isto não se aplica quando o modelo utiliza as variáveis nemp e $\mathrm{C}_{4}$ para mensurar a dimensão e a estrutura accionista da empresa. Nessa situação, a variável em causa não é estatisticamente significativa. 